\title{
Growth and grazing of microzooplankton in response to the harmful alga Heterosigma akashiwo in prey mixtures
}

\author{
Sylvia L. Graham, Suzanne L. Strom*
}

Shannon Point Marine Center, Western Washington University, 1900 Shannon Point Road, Anacortes, Washington 98221, USA

\begin{abstract}
Microzooplankton grazers may play a role in regulating blooms of the ichthyotoxic alga Heterosigma akashiwo. This study tested the effects of $H$. akashiwo, when part of a mixed-prey assemblage, on the growth and feeding of microzooplankton. Laboratory cultures of 3 ciliates, Favella sp., Metacylis sp., and Strombidinopsis acuminatum, were exposed to reciprocal concentrations of $H$. akashiwo and a non-toxic prey, at saturating prey concentrations. Heterosigma akashiwo was toxic to Favella sp. and Metacylis sp. when $H$. akashiwo was the sole prey species; however, this toxicity was eliminated in the mixed-prey treatments, likely because of avoidance of $H$. akashiwo and selective feeding on non-toxic prey. In contrast, the growth rate of $S$. acuminatum was unaffected by H. akashiwo. Both Favella sp. and S. acuminatum ingested $H$. akashiwo but selected against the alga when other prey was available. In addition, natural planktonic communities, collected from East Sound, Orcas Island, northern Puget Sound, in September and October 2007, were exposed to bloomlevel concentrations of $H$. akashiwo. Abundances of the major microzooplankton types, primarily ciliates and Gyrodinium/Gymnodinium dinoflagellates, were unaffected by $H$. akashiwo, although slight changes in grazer size structure did occur. Heterosigma akashiwo was harmful to the smallest grazers, mainly aloricate ciliates and small Gyrodinium/Gymnodinium dinoflagellates, and beneficial to larger Gyrodinium/Gymnodinium dinoflagellates that were able to ingest and grow on the alga. The alga was not consumed by the majority of grazers. Preferential feeding on alternate prey reduces toxic effects of $H$. akashiwo on microzooplankton. Avoidance of $H$. akashiwo by a major group of grazers would promote bloom formation by reducing $H$. akashiwo mortality and focusing community grazing pressure on potential competitor species.
\end{abstract}

KEY WORDS: Heterosigma akashiwo - Microzooplankton · Harmful algal blooms · Favella · Metacylis $\cdot$ Strombidinopsis

Resale or republication not permitted without written consent of the publisher

\section{INTRODUCTION}

Heterosigma akashiwo is a bloom-forming planktonic flagellate in the class Raphidophyceae of the phylum Ochrophyta (Graham \& Wilcox 2000). It occurs worldwide and is one of the most ichthyotoxic species of phytoplankton, having a large effect on local marine ecosystems and economies (Honjo 1993). Heterosigma akashiwo blooms have caused serious damage to fish culture operations in numerous Pacific Rim countries. Mass mortalities of yellowtail and red sea bream have been recorded in Japan, resulting in economic losses of over 2 billion yen during a 16 yr period (Honjo 1994). Major salmon mortalities have been documented in New Zealand, Canada, Chile, and the United States (Smayda 1998). Heterosigma akashiwo blooms have also been associated with a decrease in wild fish and invertebrate populations in the Gulf of Mexico (Livingston 2007). In the Pacific Northwest, H. akashiworelated fish mortalities were first reported at Lummi Island, Washington, in 1976 and at Nanoose Bay, British Columbia, in 1986. Recently, extensive blooms in northern Puget Sound occurred in the early summers of 2006 and 2007 (S. L. Strom pers. obs.). Eco- 
nomic losses to the regional salmon farming industry exceeded \$15 million Canadian from 1986 to 1990 (Black et al. 1991).

The mechanism of ichthyotoxicity is not well understood for this species, although several hypotheses are being explored. One hypothesis is that mucus, secreted by the alga to encapsulate non-motile cell masses, sticks to gill lamellae and results in respiratory and osmoregulatory failure (Smayda 1998). Research has also focused on damage to gill structure and function by reactive oxygen species (ROS) produced by the alga, which may lead to asphyxiation (Yang et al. 1995, Oda et al. 1997, Twiner \& Trick 2000). A neurotoxin, rather than physical damage to gill structure, may instead be responsible for fish mortality (Black et al. 1991). Production of brevetoxin-like neurotoxins has been reported for several strains (Khan et al. 1997). Heterosigma akashiwo may have several mechanisms of toxicity that produce different effects in different marine organisms. Recently, H. akashiwo has been shown to induce sublethal effects in the oyster Crassostrea virginica (Keppler et al. 2005) and to alter the metabolic activity of mammalian cells (Twiner et al. 2004). At this time, there is no accepted chemical measure of toxin content in this species (Clough \& Strom 2005).

Much research has focused on the effects of Heterosigma akashiwo on fish species; however, negative effects of this alga on microzooplankton grazers may partially explain how blooms of this harmful species arise and persist. Microzooplankton grazers are often the major consumers of phytoplankton similar in size and morphology to H. akashiwo (Sherr \& Sherr 1994). Microzooplankton play a major role in marine ecosystems as they are responsible for the majority of phytoplankton consumption and the regeneration of nutrients, and they constitute a vital food source for larger zooplankton (Sherr \& Sherr 1994). As the main consumers of phytoplankton, microzooplankton significantly affect phytoplankton population growth rates (Calbet \& Landry 2004). Furthermore, certain microzooplankton species graze on harmful algal species and likely play a role in regulating harmful algal bloom development (Watras et al. 1985, Nakamura et al. 1996, Matsuyama et al. 1999, Calbet et al. 2003, Jeong et al. 2003, 2007). Yet algal blooms, toxic or otherwise, are an indication that the growth and accumulation rates of phytoplankton cells have exceeded mortality and grazer consumption of phytoplankton (Smayda 1997). Harmful algal blooms may be due to the poisoning of grazers by algal toxins, low abundances of grazers, or other factors (Turner \& Tester 1997). Mortality of microzooplankton in the presence of $H$. akashiwo could partially explain the formation and persistence of $H$. akashiwo blooms.

Existing research shows varying responses of microzooplankton species to Heterosigma akashiwo expo- sure. Jeong et al. (2002) found the prostomatid ciliate Tiarina fusus to exhibit positive growth when exposed to increasing concentrations of $H$. akashiwo. Clough \& Strom (2005) showed that the tintinnid ciliate Eutintinnus sp. and the dinoflagellate Noctiluca scintillans derived nutritional benefit from 2 strains of $H$. akashiwo, while the ciliate Strombidium sp. and the dinoflagellate Amphidinium longum exhibited a neutral response to both strains. In contrast, both strains were toxic to 3 species of ciliates: Coxliella sp., Metacylis sp., and Strombidium sp.

Few studies have investigated the effects of harmful algal species when present as part of a mixed-prey assemblage, yet multi-species algal assemblages more accurately represent ecological conditions in coastal waters, even during harmful algal blooms. Existing studies show varying effects of mixed-prey assemblages on the toxicity of harmful algal species. The presence of a beneficial prey species, Rhodomonas sp., did not reduce Heterosigma akashiwo-related mortality in the 3 ciliate species examined by Clough \& Strom (2005). Conversely, negative effects of $H$. akashiwo on the calanoid copepod Acartia tonsa were reduced when the alga was offered with a beneficial prey species (Colin \& Dam 2002).

The aim of our study was to observe the effects of Heterosigma akashiwo on the growth and feeding of microzooplankton grazers when it is part of a mixedprey assemblage. We used a $H$. akashiwo strain isolated in 2006 from a fish-killing bloom in northern Puget Sound. Our study addressed 2 questions: (1) Does $H$. akashiwo, when mixed with non-toxic prey, affect the growth and grazing of microzooplankton grazers? (2) Do local microzooplankton communities exposed to bloom-level concentrations of $H$. akashiwo (a) ingest the alga and/or (b) change in structure?

\section{MATERIALS AND METHODS}

Laboratory cultures. A strain of Heterosigma akashiwo was isolated from northern Puget Sound $\left(48^{\circ} 37^{\prime} \mathrm{N}, 122^{\circ} 52^{\prime} \mathrm{W}\right)$ in June 2006 and deposited with the Center for Culture of Marine Phytoplankton (CCMP) in Boothbay, ME, USA. This strain, CCMP 2809, was used for all toxicity experiments. Heterocapsa triquetra and Isochrysis galbana were used as non-toxic prey for separate dual-prey experiments because they were a component of grazer maintenance prey mixtures. Carbon content, measured by carbon, hydrogen, nitrogen (CHN) analysis (Hedges \& Stern 1984), and size (length [L] and width [W]) of algal cells were as follows: $H$. triquetra: $1.1 \mathrm{ngC} \mathrm{cell}^{-1}, 20 \mu \mathrm{m}$ $\mathrm{L} \times 15 \mu \mathrm{m} \mathrm{W}$; H. akashiwo: $329.3 \mathrm{pgC}^{-1} \mathrm{cell}^{-1}, 22 \mu \mathrm{m} \mathrm{L} \times$ $18 \mu \mathrm{m} \mathrm{W}$; and I. galbana: $9.8 \mathrm{pgC}$ cell $^{-1}, 5 \mu \mathrm{m} \mathrm{L} \times 5 \mu \mathrm{m}$ 
W. Algal cultures were maintained in $\mathrm{f} / 2$ medium at $15^{\circ} \mathrm{C}$, salinity approximately 30 and $112 \mu \mathrm{mol}$ photons $\mathrm{m}^{-2} \mathrm{~s}^{-1}$ in a $12: 12 \mathrm{~h}$ light:dark cycle (Clough \& Strom 2005).

Three ciliate grazer species were used in the dual-prey experiments: 2 tintinnid ciliates, Favella sp. and Metacylis sp., and a naked spirotrich (oligotrich) ciliate, Strombidinopsis acuminatum. Grazers were maintained at $15^{\circ} \mathrm{C}$ and approximately $3.8 \mu \mathrm{mol}$ photons $\mathrm{m}^{-2} \mathrm{~s}^{-1}$ in a $12: 12 \mathrm{~h}$ light:dark cycle with biweekly inoculation of the following mixed-algal diets: Mantoniella squamata, Karlodinium veneficum, Isochrysis galbana, and Heterocapsa triquetra for Favella sp.; H. triquetra, Heterocapsa rotundata, Rhodomonas sp., Dunaliella tertiolecta, and I. galbana for S. acuminatum (Clough \& Strom 2005); I. galbana, Emiliania huxleyi, Synechococcus sp. strain CC9605, and Micromonas pusilla for Metacylis sp. A trace metal-enriched seawater medium at salinity 30 was used for grazer maintenance and all dual-prey experiments. Incubation conditions for dual-prey experiments were the same as those for grazer culture maintenance.

Dual-prey experiments. Preliminary numerical response experiments established that a prey concentration of $200 \mu \mathrm{gC}^{-1}$ resulted in saturated growth for all 3 grazer species, and this was used as the total prey concentration for the dual-prey experiments. Favella sp. and Strombidinopsis acuminatum cultures were removed from their maintenance food $24 \mathrm{~h}$ after their last feeding by sieving and reverse-sieving, respectively. Reverse-sieving isolates grazers as a sieve is inserted into the stock culture and a pipette is used to remove culture media and algal prey that pass through the sieve. Afterward, both cultures were pre-

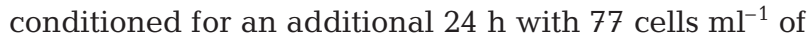
Heterocapsa triquetra. Metacylis sp. was not preconditioned prior to experimentation. Instead, Metacylis sp. was sieved from its maintenance food $24 \mathrm{~h}$ after its last feeding, and the experiment was initiated within the following $3 \mathrm{~h}$.

Average initial grazer concentrations were as follows: Favella sp., 1.8 cells ml $^{-1}$; Strombidinopsis acuminatum, 2.7 cells $\mathrm{ml}^{-1}$; and Metacylis sp., 2.6 cells $\mathrm{ml}^{-1}$. Grazers were exposed to 5 prey treatments consisting of reciprocal proportions of 2 prey types, Heterosigma akashiwo and a non-toxic prey, all containing a total prey concentration of $200 \mu \mathrm{gC}^{-1}$ (Table 1). The non-toxic prey species were Heterocapsa triquetra for Favella sp. and S. acuminatum, and Isochrysis galbana for Metacylis sp. The 5 prey treatments and a starved control were prepared in quadruplicate. Volume of algal culture added to the treatments ranged from 0.073 to $0.301 \mathrm{ml} \mathrm{H}$. triquetra, from 0.229 to
$0.916 \mathrm{ml} \mathrm{H}$. akashiwo, and from 0.110 to $0.440 \mathrm{ml} I$. galbana.

The agent of toxicity to planktonic grazers is unknown for Heterosigma akashiwo; therefore, we chose to define toxicity on the basis of the biological response of co-occurring species. Toxicity was defined as growth or mortality below that of the starved control. Grazer mortality was calculated from cell loss. Ciliates disappear soon after death, making cell loss a suitable measurement of mortality. The experiments conducted with $H$. akashiwo and Heterocapsa triquetra also included triplicate algae-only bottles of each prey proportion, which were used to determine algal growth during the experimental period. Polycarbonate bottles were used and filled completely to hold a total of $45 \mathrm{ml}$. Initial samples were fixed immediately to estimate actual grazer concentrations at the start of the experiment. Bottles were incubated at $15^{\circ} \mathrm{C}$ and $20.8 \mu \mathrm{mol}$ photons $\mathrm{m}^{-2} \mathrm{~s}^{-1}$. Favella sp. and Strombidinopsis acuminatum were incubated for $24 \mathrm{~h}$, and Metacylis sp. was incubated for $8.5 \mathrm{~h}$. Metacylis sp. required a shorter incubation period to avoid complete mortality in all $H$. akashiwo treatments so that a toxicity gradient could be observed. Samples were fixed in $2 \%$ acid Lugol's solution.

Grazers were enumerated using inverted light microscopy for the entire sample volume, less the approximately $3 \mathrm{ml}$ removed for algal quantification. The equations of Frost (1972) and Heinbokel (1978) were used to calculate grazer growth rates $\left(\mu, \mathrm{d}^{-1}\right)$, algal growth rate $\left(\mathrm{k}, \mathrm{d}^{-1}\right)$ and ingestion rates $\left(\mathrm{ngC}_{\text {grazer }}{ }^{-1}\right.$ $\mathrm{d}^{-1}$ ) for experiments with Favella sp. and Strombidinopsis acuminatum. Initial algal concentrations were estimated from counts of algal stock cultures and known addition volumes. Final algal concentration was estimated by light microscopy. Out of a total of 60 grazing rate estimates, 3 were negative and were entered as zero for further ingestion calculations, in order to reflect more accurate grazing levels. 
Natural planktonic communities. The response of natural planktonic communities to simulated Heterosigma akashiwo blooms was studied by introducing bloom-density concentrations of $H$. akashiwo cells to whole seawater samples. A target concentration of 6000 cells ml ${ }^{-1}$ was used based upon densities of a naturally occurring $H$. akashiwo bloom sampled in northern Puget Sound in June 2006. Seawater samples for experiments were collected from East Sound, Orcas Island, northern Puget Sound $\left(48^{\circ} 37^{\prime} \mathrm{N}, 122^{\circ} 52^{\prime} \mathrm{W}\right)$. East Sound is an optimal collection location because the sheltered fjord experiences frequent mixing and stratification events, resulting in episodically elevated phytoplankton and microzooplankton abundance (Jensen 2007). Seawater samples were collected and experiments conducted on 5 separate days during September and October, 2007.

Prior to water collection, vertical profiles of salinity, temperature, and fluorescence were measured with a conductivity, temperature, and depth (CTD) profiler (Sea-Bird Electronics) in order to compare hydrography and chlorophyll data with community composition. Near-surface water $(\sim 0.5 \mathrm{~m})$ was then collected with a 41 Niskin bottle. Silicon tubing was used to transfer seawater from the Niskin bottle into 2 carboys. During transfer, seawater was screened through $200 \mu \mathrm{m}$ mesh to remove macrozooplankton so that the response of protist grazers would not be masked by higher trophic level interactions. Three collections were necessary to obtain the required volume of water. Gloves were used to handle all tubing and mesh in order to prevent contamination. Carboys were covered in black plastic until arrival at the laboratory, approximately $2 \mathrm{~h}$ after water collection, at which point they were placed in a temperature-controlled room for the remaining experimental setup.

Quadruplicate $500 \mathrm{ml}$ polycarbonate bottles were prepared for the following 3 treatments: $(1)<200 \mu \mathrm{m}$ screened seawater with addition of $\mathrm{f} / 2$ medium (control), (2) $<200 \mu \mathrm{m}$ screened seawater with addition of Heterosigma akashiwo cells, and (3) $0.2 \mu \mathrm{m}$ filtered seawater with addition of $H$. akashiwo cells. The $0.2 \mu \mathrm{m}$ filtered seawater with added $H$. akashiwo (Treatment [Tmt] 3) was used to calculate the growth rate of the alga during the experiment. This value was used to estimate the contribution of $H$. akashiwo growth to changes in $H$. akashiwo concentration within the microzooplankton community treatment (Tmt 2). In order to maintain equivalent nutrient levels between treatments, f/2 medium was added to Tmt 1 , at a volume equal to that of the algal culture added to Tmts $2 \& 3$.

Four experiments received the target algal concentration of 6000 cells ml $^{-1}$; however, the algal culture did not reach adequate density for the first sampling day, resulting in a concentration of approximately 3000 cells $\mathrm{ml}^{-1}$ for that day. Algal culture and $\mathrm{f} / 2$ medium were distributed into experimental bottles, followed by the addition of seawater. Seawater from 1 carboy was siphoned into bottles for Tmts 1 and 2 in a haphazard order. Initial samples for quantifying microzooplankton abundance were also taken from this carboy and fixed immediately. In order to equally distribute planktonic organisms, water within this carboy was gently mixed with a plunger prior to and during the transfer to experimental bottles. Seawater from the second carboy was filtered through a $0.2 \mu \mathrm{m}$ cartridge filter and distributed into Tmt 3 bottles.

Bottles were put into 1-layer screen bags and placed outside on a rotating plankton wheel (approximately $0.5 \mathrm{rpm})$, submerged in a flow-through seawater system to maintain ambient seawater temperature and light level. In order to identify consumers and determine ingestion rates of Heterosigma akashiwo, $100 \mathrm{ml}$ samples from Tmt 2 were preserved at 0 and $1 \mathrm{~h}$ and filtered for epifluorescence microscopy. Samples were preserved in $1 \%$ glutaraldehyde, and slides were prepared with $20 \mu \mathrm{m}$ pore size, $25 \mathrm{~mm}$ diameter polycarbonate filters. Cells were stained with $10 \mathrm{\mu g} \mathrm{ml}^{-1}$ DAPI stain in order to observe cell nuclei for grazer identification. Nuclear characteristics were observed using an ultraviolet (UV, 340 to $380 \mathrm{~nm}$ bandpass) excitation filter. Algal cells were observed using a blue 450 to $490 \mathrm{~nm}$ bandpass excitation filter. Organisms were identified on the basis of morphology, size, nuclei, presence of cilia, and presence and pattern of chloroplasts. The number of ingested $H$. akashiwo cells was quantified for at least 100 individuals of the more abundant grazer types. Ingestion rate $(H$. akashiwo cells ingested grazer ${ }^{-1} \mathrm{~h}^{-1}$ ) was calculated for each major consumer by dividing the number of ingested $H$. akashiwo cells by the number of that particular grazer within 1 sample. For each grazer type found to ingest H. akashiwo, 30 individuals were measured to obtain length and width dimensions using Image-Pro Plus 5.0 software.

For determination of microzooplankton community changes in response to Heterosigma akashiwo, $125 \mathrm{ml}$ samples from Tmts 1 and 2 were preserved in $10 \%$ acid Lugol's solution at 0 and $24 \mathrm{~h}$. A higher concentration of acid Lugol's solution was used to preserve field samples owing to the range of planktonic ciliates within a sample. Inverted light microscopy was used to observe a settled volume of each sample containing at least 200 organisms longer than $20 \mu \mathrm{m}$. Dinoflagellates longer than $20 \mu \mathrm{m}$ and all ciliates were quantified. Microbiota software (Roff \& Hopcroft 1986) was used to measure the length and width of each individual, to calculate biovolume, and to estimate carbon content based on published carbon-to-volume ratios. In order to estimate community grazing on $H$. akashiwo, $20 \mathrm{ml}$ 
samples from Tmts $2 \& 3$ were preserved in $1 \%$ acid Lugol's solution after 0,8 , and 24 h. H. akashiwo cells were quantified using a Sedgewick-Rafter chamber, and algal growth $\left(\mathrm{k} \mathrm{d}^{-1}\right)$ and grazing $\left(\mathrm{g} \mathrm{d}^{-1}\right)$ rates were calculated (Frost 1972).

Statistical analysis. In the dual-prey experiments, growth rate of Favella sp. was analyzed using a 1-way ANOVA and the Student-Newman-Keuls post-hoc test for multiple comparisons with SPSS 15.0 software. Growth rates of Strombidinopsis acuminatum and Metacylis sp. did not meet the assumption of equality of variances despite the use of several data transformation methods. Therefore a Kruskal-Wallis test was used to analyze the growth rates of those grazers with Statistix 1 software (Analytical Software).

In the natural planktonic community experiments, microzooplankton abundance and biomass were analyzed using multi-dimensional scaling (MDS) ordination and analysis of similarity (ANOSIM) with Primer 6. Data were square-root transformed to reduce the contribution of the more abundant microzooplankton types. Ordinations were made from Bray-Curtis similarities.

\section{RESULTS}

\section{Dual-prey experiments}

Growth rates of Favella sp. differed significantly among prey treatments (ANOVA, $F=4.207, \mathrm{p}<0.01$ ). Favella sp. showed significantly increased mortality in the $100 \%$ Heterosigma akashiwo treatment versus the starved control, with average growth rates of -0.36 and $-0.08 \mathrm{~d}^{-1}$, respectively, signifying a toxic effect of the alga (Fig. 1a,b). Growth rates in treatments with the non-toxic prey, Heterocapsa triquetra, were not significantly different from the starved control (StudentNewman-Keuls test, $\mathrm{p}>0.05$ ), indicating that the presence of $H$. triquetra eliminated the toxic effect of $H$. akashiwo.

Growth rate of Strombidinopsis acuminatum was also significantly different among the different prey treatments (Kruskal-Wallis statistic $=15.256$, $\mathrm{p}=0.009)$. Growth rates increased with increasing concentrations of Heterocapsa triquetra, with a significant difference between the starved and $100 \% H$. triquetra treatments, averaging -0.11 and $0.17 \mathrm{~d}^{-1}$, respectively (Fig. 1c,d). No toxic effect of Heterosigma akashiwo was observed.

Growth rate of Metacylis sp. also varied with prey treatments (KruskalWallis statistic $=20.235, p=0.001)$. The
$100 \%$ Heterosigma akashiwo treatment induced significantly greater mortality than the starved control, with average growth rates of -2.62 and $-0.18 \mathrm{~d}^{-1}$, respectively, signifying a toxic effect of the alga (Fig. 1e,f). The growth rates of Metacylis sp. in the treatments with Heterocapsa triquetra were not significantly different than those in the starved control, a response similar to that observed for Favella sp.

Algal growth rates in algae-only controls from the first experiment were close to zero for both prey species (Table 2). Ingestion of Heterosigma akashiwo by Favella sp. was near zero for the 25 and $50 \% \mathrm{H}$. akashiwo treatments and rose slightly for the 75 and $100 \% H$. akashiwo treatments, with averages ranging from 4.2 to $18.4 \mathrm{ngC}$ grazer $^{-1} \mathrm{~d}^{-1}$, or from 12.9 to 55.9 prey cells grazer ${ }^{-1} \mathrm{~d}^{-1}$ (Fig. 2). Ingestion of Heterocapsa triquetra also increased with increasing concentrations of that species, but to a greater degree, with averages ranging from 13.8 to $49.7 \mathrm{ngC}$ grazer $^{-1} \mathrm{~d}^{-1}$, or from 12.6 to 45.1 prey cells grazer ${ }^{-1} \mathrm{~d}^{-1}$. Ingestion in the $100 \% H$. triquetra treatment was higher, although not significantly so, than in the $100 \% H$. akashiwo treatment $\left(F_{1,6}=5.742, \mathrm{p}=0.054\right)$. Ingestion of $H$. akashiwo by Strombidinopsis acuminatum remained low at all concentrations of the alga, with averages ranging from 2.7 to $10.3 \mathrm{ngC}$ grazer $^{-1} \mathrm{~d}^{-1}$, or from 8.1 to 31.4 prey cells grazer $^{-1} \mathrm{~d}^{-1}$. Conversely, ingestion of $H$. triquetra increased with increasing concentrations of that species, with averages ranging from 17.1 to $59.4{\mathrm{ngC} \text { grazer }^{-1}}^{-}$ $\mathrm{d}^{-1}$, or from 15.5 to 54.0 prey cells grazer ${ }^{-1} \mathrm{~d}^{-1}$. Ingestion in the $100 \% H$. triquetra treatment was significantly higher than in the $100 \% \mathrm{H}$. akashiwo treatment, with averages of 59.4 and $6.12 \mathrm{ngC}$ grazer ${ }^{-1} \mathrm{~d}^{-1}$, respectively (ANOVA, $F=532.04, \mathrm{p}<0.0001$ ). Both grazer species selected against $H$. akashiwo when it was offered in combination with $H$. triquetra, as proportional ingestion of the raphidophyte consistently remained below its proportionate contribution to prey availability (Fig. 3). This was the case when ingestion was calculated on the basis of either prey carbon or prey cell number.

Table 2. Mean algal growth rate $\mathrm{k}\left(\mathrm{d}^{-1}\right)$ and ingestion rate $\left(\mathrm{ngC}\right.$ grazer ${ }^{-1} \mathrm{~d}^{-1}$ and prey cells grazer ${ }^{-1} \mathrm{~d}^{-1}$ ) by Favella sp. and Strombidinopsis acuminatum for the $100 \%$ Heterosigma akashiwo and $100 \%$ Heterocapsa triquetra treatments of the dual-prey experiments $(n=4)$. Total prey concentration was $200 \mu \mathrm{gC}^{-1}$. SD is shown in parentheses

\begin{tabular}{|c|c|c|c|c|c|}
\hline \multirow{2}{*}{ Treatment } & \multirow{2}{*}{$\begin{array}{c}\mathrm{k} \\
\left(\mathrm{d}^{-1}\right)\end{array}$} & \multicolumn{4}{|c|}{ - Ingestion- } \\
\hline & & $\begin{array}{r}\mathrm{ngC} \mathrm{g} \\
\text { Favella sp. }\end{array}$ & $\begin{array}{l}\text { rrazer }{ }^{-1} \mathrm{~d}^{-1} \\
\text { S. acuminatum }\end{array}$ & $\begin{array}{r}\text { Prey cel } \\
\text { Favella sp. }\end{array}$ & $\begin{array}{l}\text { s grazer }{ }^{-1} \mathrm{~d}^{-1} \\
\text { S. acuminatum }\end{array}$ \\
\hline $\begin{array}{l}100 \% \\
\text { H. triquetra }\end{array}$ & $\begin{array}{l}-0.067 \\
(0.075)\end{array}$ & $\begin{array}{c}49.7 \\
(3.46)\end{array}$ & $\begin{array}{c}59.4 \\
(3.91)\end{array}$ & $\begin{array}{c}45.1 \\
(3.15)\end{array}$ & $\begin{array}{c}54.0 \\
(3.55)\end{array}$ \\
\hline $\begin{array}{l}100 \% \\
\text { H. akashiwo }\end{array}$ & $\begin{array}{l}-0.075 \\
(0.037)\end{array}$ & $\begin{array}{c}18.4 \\
(15.91)\end{array}$ & $\begin{array}{c}6.12 \\
(2.46)\end{array}$ & $\begin{array}{c}55.9 \\
(48.31)\end{array}$ & $\begin{array}{c}18.6 \\
(7.46)\end{array}$ \\
\hline
\end{tabular}



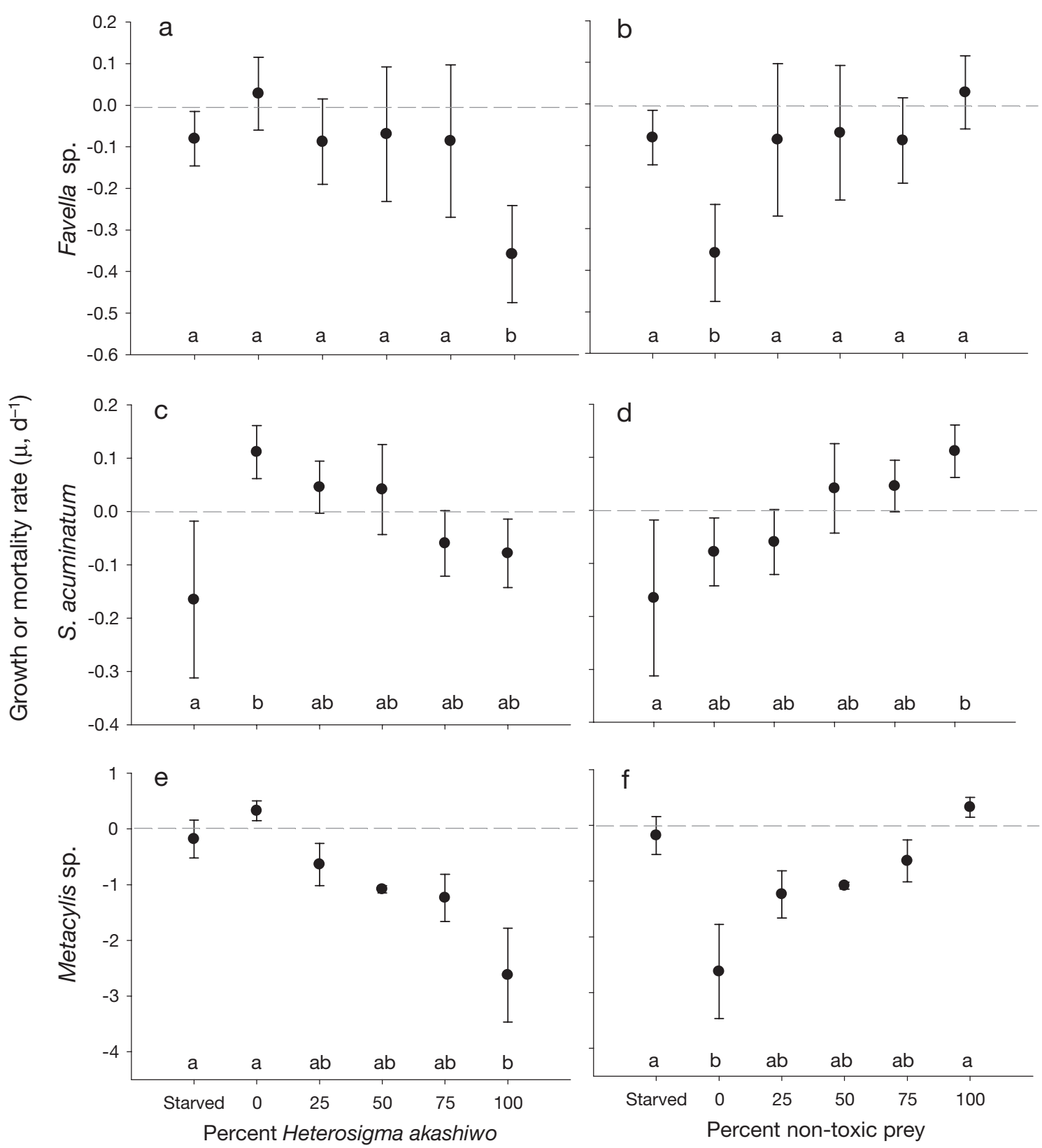

Fig. 1. Growth or mortality rate $\left(\mu, \mathrm{d}^{-1}\right)$ of $(\mathrm{a}, \mathrm{b})$ Favella sp., $(\mathrm{c}, \mathrm{d})$ Strombidinopsis acuminatum, and (e,f) Metacylis sp. exposed to inverse proportions of Heterosigma akashiwo plus non-toxic prey and a starved control. The non-toxic prey were Heterocapsa triquetra for Favella sp., and S. acuminatum and Isochrysis galbana for Metacylis sp. Growth rates are shown both as a function of percent $H$. akashiwo $(\mathrm{a}, \mathrm{c}, \mathrm{e})$ and non-toxic prey $(\mathrm{b}, \mathrm{d}, \mathrm{f})$. Treatments with the same letters are not significantly different (post-hoc Student-Newman-Keuls comparison, Favella sp.; comparison of mean ranks, S. acuminatum and Metacylis sp.). Error bars represent $\pm 1 \mathrm{SD}$

\section{Natural planktonic communities}

Salinity values increased during the September to October study period, ranging from 29.5 to 30.5 (Table 3 ). Concurrently, seawater temperature decreased from 12.6 to $10.6^{\circ} \mathrm{C}$. In situ temperatures were within $1.4^{\circ} \mathrm{C}$ of temperatures in the flow-through seawater system in which the experimental bottles were maintained. Chlorophyll a concentrations were estimated from in situ fluorescence measurements. The first 4 collection dates showed some variability, with chlorophyll a concentrations ranging between 3.85 and $7.64 \mathrm{mg} \mathrm{m}^{-3}$, while on the final date concentrations rose considerably to $16.97 \mathrm{mg} \mathrm{m}^{-3}$. Depth profiles revealed water 

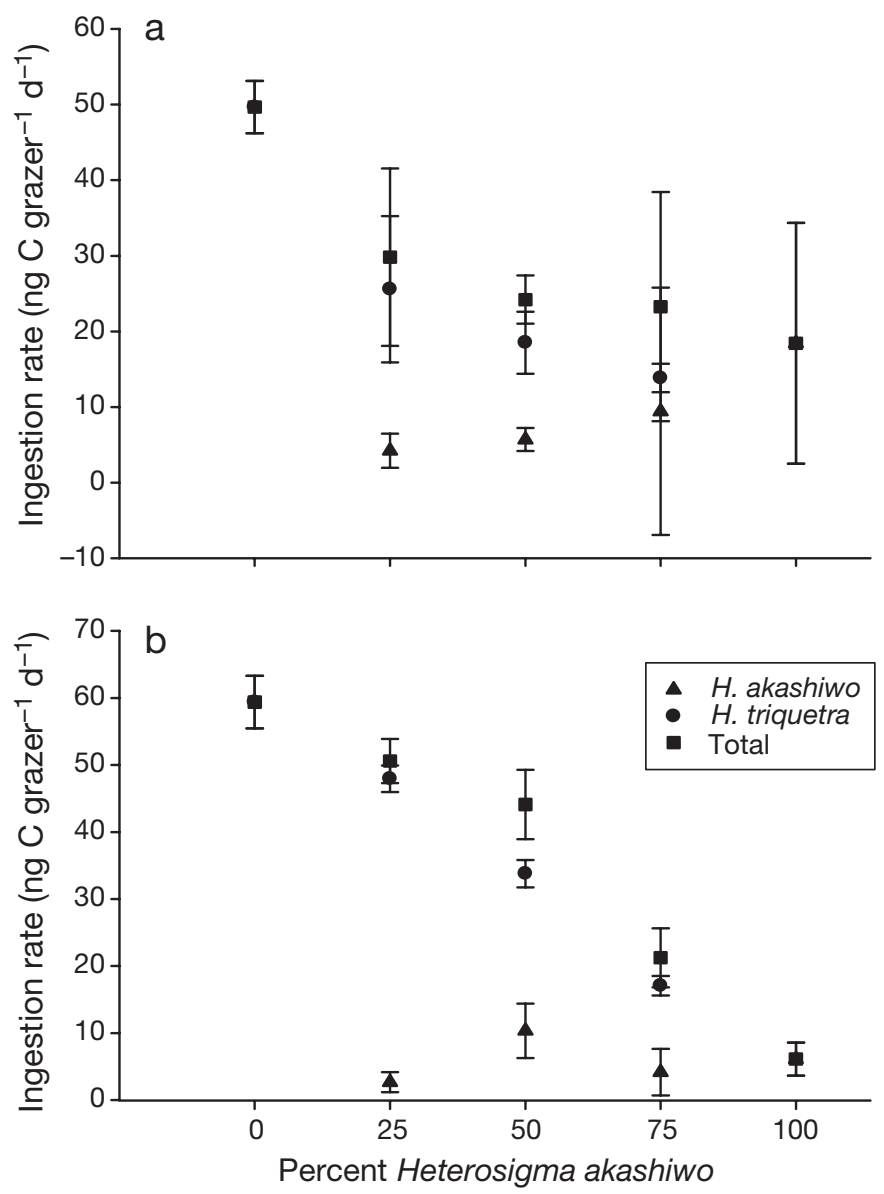

Fig. 2. Average ingestion rates (ngC grazer-1 $\mathrm{d}^{-1}$ ) of (a) Favella sp. and (b) Strombidinopsis acuminatum on Heterocapsa triquetra, Heterosigma akashiwo, and total available prey (total) in the dual-prey experiments. Error bars represent $\pm 1 \mathrm{SD}$

column stratification for each sampling date, with the pycnocline at an average of $5 \mathrm{~m}$ depth.

Average initial concentrations of added Heterosigma akashiwo ranged between 6120 and 6690 cells ml$^{-1}$ for all experiments, except for 4 September which had 2850 cells ml $\mathrm{m}^{-1}$ (Table 4). Average growth rate of $H$. akashiwo in algae-only controls ranged between 0.008 and $0.215 \mathrm{~d}^{-1}$ for all 5 experiments. Average community grazing rate on $H$. akashiwo ranged between -0.034 and $0.204 \mathrm{~d}^{-1}$, except for the 5 October experiment which had a rate of $3.11 \mathrm{~d}^{-1}$. The high grazing rate on 5 October is due to 2 replicates with rates of 5.8 and $6.4 \mathrm{~d}^{-1}$, as compared with the 2 other replicate values of -0.018 and $0.077 \mathrm{~d}^{-1}$.

The most abundant microzooplankton types during these experiments were ciliates $<40 \mu \mathrm{m}$ in length and Gyrodinium/Gymnodinium dinoflagellates from 20 to $39 \mu \mathrm{m}$ in length (Table 5). Partitioning of microzooplankton into 2 major groups of dinoflagellates and ciliates shows that dinoflagellates were the more abundant type on all dates except for 15 October. Overall microzooplankton abundance in East Sound changed throughout the sampling period. Average abundance was 35000 cells $1^{-1}$ in the initial 4 September samples, rising to 105000 cells $1^{-1}$ on 24 September and then falling to 48000 cells $1^{-1} 2$ d later on 26 September. In October, abundance decreased to below 25000 cells $1^{-1}$.

No significant treatment effect was found for abundances of the major microzooplankton types for any of the experimental dates, with Global $\mathrm{R}$ values ranging from -0.17 to 0.13 . Global $R$ values range from -1 to 1 , in which 0 signifies that the null hypothesis is true and 1 indicates that the replicates within a treatment are more similar than replicates between treatments. However, a trend of decreased abundance of oligotrich ciliates from 40 to $59 \mu \mathrm{m}$ and $>60 \mu \mathrm{m}$ in length was observed in the added Heterosigma akashiwo treatment, as compared to the control, on all of the experiment dates except 4 September, with an overall average decrease of 29 and $62 \%$, respectively. Averaging abundance data for all major microzooplankton types in each treatment within each day revealed a distinct change in overall community structure over time that was much larger than the treatment differences within a given day (Fig. 4).

Three types of microzooplankton measurably ingested Heterosigma akashiwo during the September

Table 3. Hydrography and chlorophyll measurements from the seawater collection location in East Sound, Orcas Island, northern Puget Sound, and average temperature of the flow-through seawater system in which the natural planktonic community experiment bottles were maintained. In situ measurements were recorded at $1 \mathrm{~m}$ depth with a conductivity, temperature, and depth profiler immediately prior to seawater collection. Chlorophyll a concentration was estimated from in situ fluorescence. Incubation temperature was recorded every $15 \mathrm{~min}$ at the system intake and averaged for the time period of each experiment

\begin{tabular}{|lccccc|}
\hline Date & Time & Salinity & Chlorophyll $a\left(\mathrm{mg} \mathrm{m}^{-3}\right)$ & Temperature $\left({ }^{\circ} \mathrm{C}\right)$ & Incubation temperature $\left({ }^{\circ} \mathrm{C}\right)$ \\
\hline 4 Sep & $08: 30 \mathrm{~h}$ & 29.7 & 7.64 & 12.6 & 11.3 \\
24 Sep & $09: 39 \mathrm{~h}$ & 29.5 & 5.66 & 11.9 & 11.0 \\
26 Sep & $08: 35 \mathrm{~h}$ & 29.5 & 6.27 & 12.0 & 10.7 \\
5 Oct & $08: 48 \mathrm{~h}$ & 30.0 & 3.85 & 10.8 & 10.1 \\
15 Oct & $08: 39 \mathrm{~h}$ & 30.5 & 16.97 & 10.6 & 10.1 \\
\hline
\end{tabular}




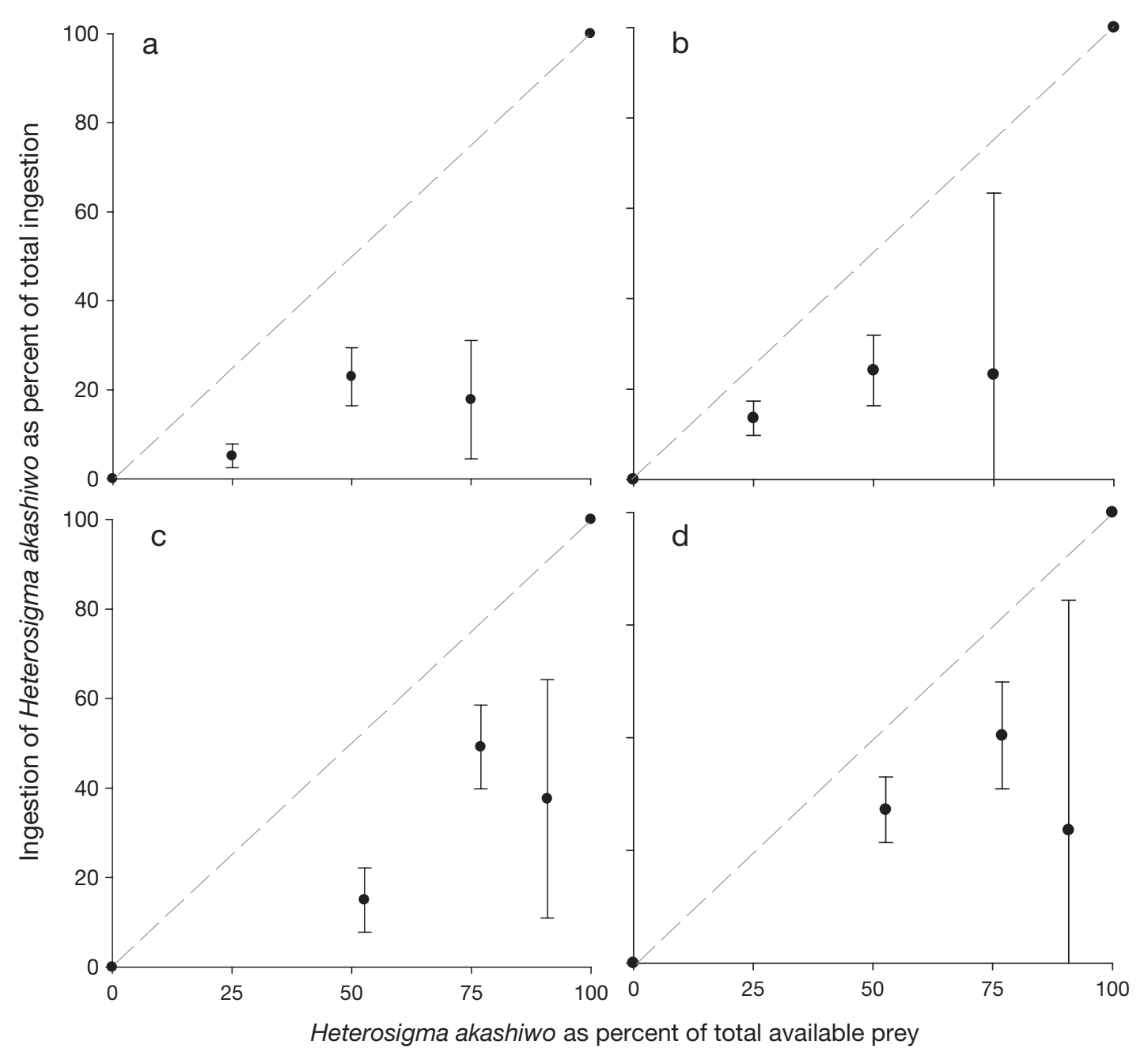

Fig. 3. Feeding selectivity plots for (a,c) Strombidinopsis acuminatum and (b,d) Favella sp. Ingestion of Heterosigma akashiwo as a percent of total ingestion is plotted against percent availability of $H$. akashiwo. Dashed lines show 1:1 relationship. Availability and ingestion are shown based on prey biomass $\left(\mu \mathrm{gC}^{-1}, \mathrm{ngC} \mathrm{grazer}^{-1} \mathrm{~d}^{-1}\right)$ in $(\mathrm{a}, \mathrm{b})$ and prey abundance $\left(\mathrm{cells} \mathrm{m}^{-1}\right.$, cells grazer ${ }^{-1}$ $\left.\mathrm{d}^{-1}\right)$ in $(\mathrm{c}, \mathrm{d})$. Error bars represent $\pm 1 \mathrm{SD}$

experiments, including an aloricate ciliate, a Gyrodinium/Gymnodinium dinoflagellate, and an unidentifiable round dinoflagellate. Average length of these organisms ranged from 30.4 to $36.5 \mu \mathrm{m}$ (Table 6). Average ingestion rates for the September experiments, based on enumeration of food vacuole contents, ranged between 0.60 and $1.10 \mathrm{H}$. akashiwo grazer ${ }^{-1}$ $\mathrm{h}^{-1}$. Ingestion of $H$. akashiwo during the October experiments was negligible.

The effect of Heterosigma akashiwo on grazer size distribution was analyzed to determine whether grazer size influenced susceptibility to the alga. High variability within treatments prevented substantial differences between treatments from emerging; however, the 24 September, 26 September, and 5 October experiments revealed 2 notable trends. Experiments on these 3 dates exhibited a decrease in the frequency of cells in the smallest size class (biovolume $750 \mu^{3}$ cell $^{-1}$ ) (equivalent spherical diameter $12.4 \mu \mathrm{m}$ ), in the $\mathrm{H}$. akashiwo treatment, with no corresponding decrease in the controls (Fig. 5; 24 September data only). This decrease was due to reduced numbers of both aloricate ciliates and small Gyrodinium/Gymnodinium dinoflagellates in the added $H$. akashiwo treatment. Secondly, experiments on 24 and 26 September showed an increase in the percentage of mid-sized grazers in the H. akashiwo treatment, with no corresponding increase in the controls. This increase occurred in grazers within the biovolume ranges of 3000 to 10000 and 4000 to $10000 \mu^{3}$ cell $^{-1}$ (equivalent spherical diameters of 19.7 to 29.4 and 21.7 to $29.4 \mu \mathrm{m}$ ) for 24 and 26 September, respectively. This increase in mid-sized grazers was primarily caused by an increase in Gyrodinium/Gymnodinium dinoflagellates in the added $H$. akashiwo treatments. 
Table 4. Heterosigma akashiwo. Average initial concentration (cells $\mathrm{ml}^{-1}$ ) and growth rate $(\mathrm{k})$ of added $H$. akashiwo, and grazing rate $(\mathrm{g})$ on $H$. akashiwo for the experiments with natural planktonic communities $(\mathrm{n}=4)$. Rates are based on samples preserved after $24 \mathrm{~h}$. SD is shown in parentheses

\begin{tabular}{|lccc|}
\hline Date & $\begin{array}{c}\text { Average initial } \\
\text { H. akashiwo concen- } \\
\text { tration (cells ml-1 }\end{array}$ & $\begin{array}{c}\mathrm{k} \\
\left(\mathrm{d}^{-1}\right)\end{array}$ & $\begin{array}{c}\mathrm{g} \\
\left(\mathrm{d}^{-1}\right)\end{array}$ \\
\hline 4 Sep & $2850(86)$ & $0.215(0.236)$ & $0.204(0.056)$ \\
24 Sep & $6270(236)$ & $0.058(0.030)$ & $0.0315(0.047)$ \\
26 Sep & $6120(323)$ & $0.022(0.029)$ & $0.070(0.053)$ \\
5 Oct & $6690(191)$ & $0.068(0.018)$ & $3.108(3.526)$ \\
15 Oct & $6550(189)$ & $0.008(0.041)$ & $-0.034(0.043)$ \\
\hline
\end{tabular}

\section{DISCUSSION}

\section{Dual-prey experiments}

Heterosigma akashiwo was toxic to both tintinnid ciliates when it was the sole food source; Favella sp. and Metacylis sp. both exhibited greater mortality in the $100 \%$ H. akashiwo treatment than in the starved control. This toxicity was not observed in treatments containing mixtures of $H$. akashiwo and non-toxic prey, even at low concentrations of the non-toxic alga. In contrast to the tintinnid ciliates, $H$. akashiwo was not toxic to the oligotrich ciliate Strombidinopsis acuminatum. The growth rate of $S$. acuminatum was unaffected by the presence of $H$. akashiwo but increased with increasing concentrations of non-toxic prey.

Favella sp. and Metacylis sp. exhibited positive, yet low, growth rates in the $100 \%$ non-toxic prey treatment, potentially because of insufficient prey diversity. This Favella species has not demonstrated substantial growth on 1 prey species alone, yet it grows well on a prey mixture that includes Heterocapsa triquetra. Secondly, the low growth rate may be due to potentially unhealthy grazers. While poor condition may have made the grazers more susceptible to toxicity, several experiments have shown Heterosigma akashiwo to be harmful to tintinnids (Verity \& Stoecker 1982, Kamiyama et al. 2000, Clough \& Strom 2005).

Both Favella sp. and Strombidinopsis acuminatum ingested Heterosigma akashiwo; however, both ciliates selected against the alga when Heterocapsa triquetra was available. This suggests that the ciliates were able to differentiate between the 2 prey species and avoided $H$. akashiwo when other prey species were available. When $H$. akashiwo was the only prey available, ingestion by $S$. acuminatum remained low, while feeding by Favella sp. increased slightly above that observed in the mixed-prey treatments. This suggests that $S$. acuminatum generally avoids consuming the alga even when it is the only available prey,

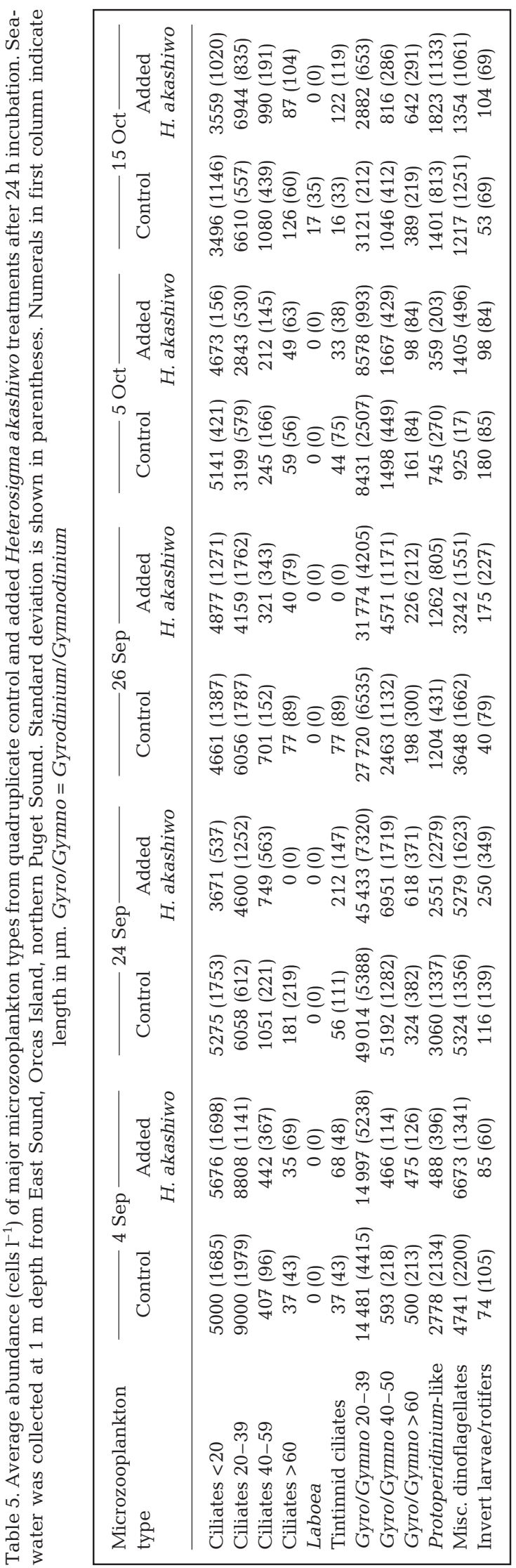




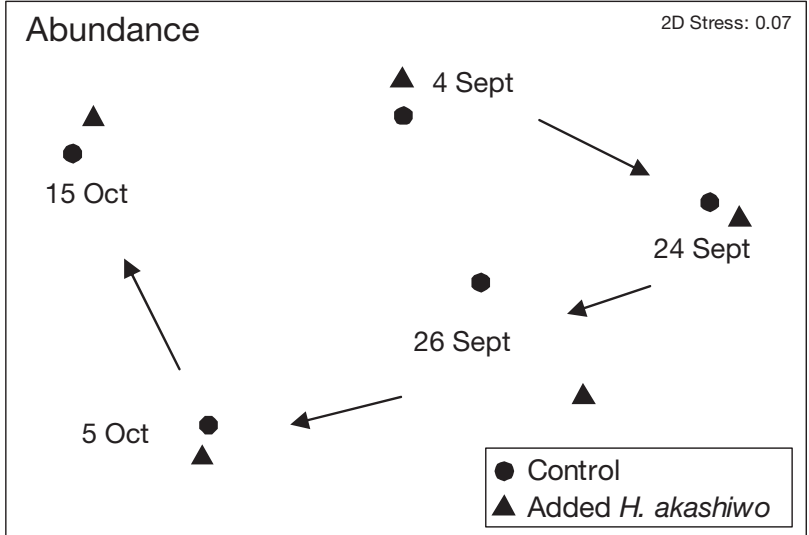

Fig. 4. Multi-dimensional scaling ordination of microzoplankton abundance (cells $\mathrm{l}^{-1}$ ) averages of the control and added Heterosigma akashiwo treatments for each experimental date

whereas Favella sp. will ingest more algae under those same conditions. Ingestion of $H$. akashiwo by Favella sp. may have occurred at the beginning of incubation and declined to near zero as the grazer experienced harmful effects of the alga that led to the higher mortality rate, as observed by Kamiyama \& Arima (2001).

The different ingestion rates between Favella sp. and Strombidinopsis acuminatum in the $100 \%$ Heterosigma akashiwo treatment may account for the difference in toxicity observed between the 2 ciliates. Toxicity may be partially or wholly induced through ingestion of the alga, which would explain why Favella sp. and not $S$. acuminatum exhibited a toxic response to the $100 \% H$. akashiwo treatment. Reduced ingestion of H. akashiwo by Favella sp. in the mixed-prey treatments could have led to the decrease in toxicity observed in those treatments. Verity \& Stoecker (1982) suggest that $H$. akashiwo (previously Olisthodiscus luteus) toxicity in Favella sp. is induced by ingestion or direct contact with the alga. Tintinnid growth rate was inhibited by $H$. akashiwo exposure, yet $H$. akashiwoconditioned media did not substantially decrease grazer growth, when also combined with alternative prey. Differential prey uptake has been observed in ciliates (Verity 1991), and Favella sp. have been shown to reject $H$. akashiwo cells (Taniguchi \& Takeda 1988, Stoecker et al. 1995), signifying selective prey consumption among grazers. If ingestion of $H$. akashiwo rises only when it is the sole prey source, and ingestion plays a role in toxicity, then the presence of alternative prey would reduce this toxicity by allowing the grazer to shift its ingestion from the raphidophyte to a more beneficial prey source.

The presence of Heterosigma akashiwo also resulted in a decrease in feeding on non-toxic prey by Favella sp. While growth rate of the grazer was not significantly inhibited in the mixed-prey treatments, ingestion of non-toxic prey was hindered. Reduced overall feeding rates may be a sublethal effect of $H$. akashiwo, which could have a stronger effect on grazer growth rate with a longer exposure period than that of our $24 \mathrm{~h}$ experiments. Egloff (1986) also observed reduced feeding on non-toxic prey in rotifers exposed to $H$. akashiwo.

Selective feeding and toxicity depend on prey concentration. Colin \& Dam (2002) tested the toxicity of another Heterosigma species, Heterosigma carterae, on the copepod Acartia tonsa in single- and mixedprey treatments, with algal concentrations similar to those used here. As in our study, they found reduced toxicity in the mixed-prey treatments at similarly low concentrations of the harmful alga. In contrast, in at least some cases the beneficial effects of alternative prey do not occur at higher concentrations of harmful algae. Clough \& Strom (2005) used a Heterosigma akashiwo concentration of 2000 cells $\mathrm{ml}^{-1}$, as compared to the concentrations in our study ranging from 152 to 607 cells $\mathrm{ml}^{-1}$. In addition, Clough \& Strom (2005) used a different strain of the alga, which may have differed in physiology, including toxicity, from the strain used in our study (K. A. Fredrickson, R. Crim, K. Coyne, S. L. Strom unpubl.). This higher H. akashiwo concentration, along with interstrain differences, may explain the toxicity observed in their mixed-prey treatments, which was not seen in our study. Natural $H$. akashiwo blooms containing high concentrations of the alga have also caused significant decreases in tintinnid ciliate abundances, despite the

Table 6. Average ingestion rate (Heterosigma akashiwo cells ingested grazer ${ }^{-1} \mathrm{~h}^{-1}$ ) and average length and width ( $\left.\mu \mathrm{m}\right)$ of microzooplankton grazers from the natural planktonic community experiments conducted in September 2007. Rates are based on samples preserved after $1 \mathrm{~h}$. SD is shown in parentheses

\begin{tabular}{|lllc|}
\hline Date & Grazer type & $\begin{array}{c}\text { Average length and } \\
\text { width }(\mu \mathrm{m})\end{array}$ & $\begin{array}{c}\text { Average ingestion rate } \\
\left(\text { H. akashiwo } \text { cells } \text { ingested } \text { grazer }^{-1} \mathrm{~h}^{-1} \text { ) }\right.\end{array}$ \\
\hline 4 Sep & Aloricate ciliate & $36.5(4.9) \times 28.1(4.3)$ & $1.10(0.05)$ \\
24 Sep & Gyrodinium/Gymnodinium & $30.8(5.8) \times 15.3(3.3)$ & $0.60(0.05)$ \\
26 Sep & Gyrodinium/Gymnodinium & $30.4(4.9) \times 17.6(3.6)$ & $0.61(0.09)$ \\
26 Sep & Round dinoflagellate & $31.7(5.0) \times 22.5(3.2)$ & $0.63(0.07)$ \\
\hline
\end{tabular}



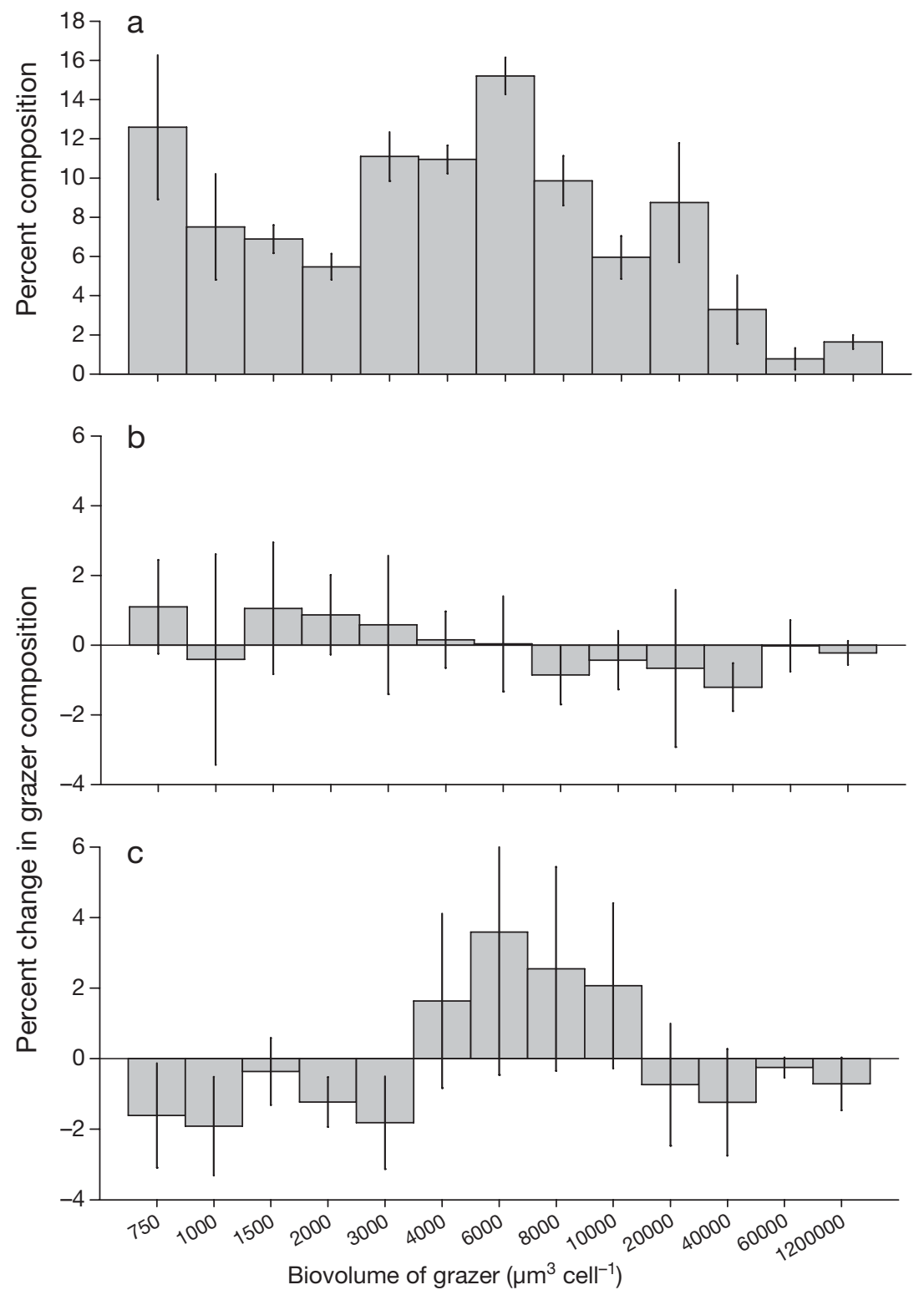

Fig. 5. (a) Percent composition of grazer sizes in the initial samples, and (b,c) the percent change in grazer size composition after $24 \mathrm{~h}$ for (b) the control and (c) added Heterosigma akashiwo treatments for the experiment conducted on 24 September 2007. Percent change in grazer size composition was calculated by subtracting the initial sample average from each of the 2 treatments. Error bars represent $\pm 1 \mathrm{SD}$

presence of alternative prey species within the bloom (Kamiyama et al. 2000). The beneficial effects of alternative prey may be dependent upon relatively low concentrations of Heterosigma sp.; however, additional evidence shows that this concentration-dependence is not universal. Hansen (1995) found the beneficial effects of alternative prey to occur in the presence of much higher concentrations of the toxic dinoflagellate Gyrodinium aureolum (presently Karenia mikimotoi). Favella ehrenbergii growth remained unaffected by up to 4000 cells $\mathrm{ml}^{-1}$ of $G$. aureolum when it was mixed with an equal ratio of beneficial prey. Harmful algal species are not all equally toxic, and $G$. aureolum may be less toxic than $H$. akashiwo to Favella sp. Thus, the effects of prey concentration on toxicity will vary depending on the algal species and strain being used.

Considering the low Heterosigma akashiwo concentrations used in our study, one might conclude that the lower $H$. akashiwo concentrations, and not the presence of non-toxic prey, led to the reduction in toxicity in the mixed-prey treatments. In the case of Favella sp., it is most likely the presence of non-toxic prey that reduced the toxicity, because concentrations of the same strain of $H$. akashiwo as low as 100 cells $\mathrm{ml}^{-1}$ are toxic to this grazer (S. L. Strom \& K. A. Fredrickson unpubl. data). This algal concentration is below that of the $25 \% \mathrm{H}$. akashiwo treatment in our experiment of 152 cells $\mathrm{ml}^{-1}$, thus indicating that the decrease in toxicity in the mixed-prey treatments is due to the added non-toxic algae and not to a reduced abundance of $H$. akashiwo.

Ciliates are not uniformly susceptible to toxicity by harmful algal species. Favella sp. have exhibited increased growth and grazing with exposure to blooms of the harmful dinoflagellates Heterocapsa circularisquama (Kamiyama \& Matsuyama 2005) and Gonyaulax tamarensis (Watras et al. 1985). Likewise, Strombidinopsis spp. also show varying responses to other harmful algal species. Strombidinopsis sp. exhibited increased mortality with exposure to the alga Prymnesium parvum (Rosetta \& McManus 2003) and the dinoflagellate Lucialla masanensis. Conversely, Strombidinopsis jeokjo readily ingested and grew on the dinoflagellates Pfiesteria piscicida, Stoeckeria algicida (Jeong et al. 2007), and Cochlodinium polykrikoides (Jeong et al. 2008). Different toxicity responses may be due to varying modes of toxicity among harmful algal species, as well as diverse cellular and behavioral characteristics among grazers. Furthermore, alternative, non-toxic prey species vary in the degree to which they reduce the toxic effects of harmful algae (Rosetta \& McManus 2003). Therefore, the results of mixed-prey experiments will depend upon the specific grazer, non-toxic prey, and harmful algal species being used. 


\section{Natural planktonic communities}

The natural planktonic community experiments tested the effects of Heterosigma akashiwo exposure on many types of microzooplankton. Each sampling date revealed a different community based on the abundance of major microzooplankton groups, which provided a variety of communities in which to test the effects of $H$. akashiwo. The change in community structure observed among the sampling dates is likely related in part to the observed shifts in hydrography over time. We observed a distinct shift in temperature and salinity between the $2 \mathrm{mo}$, with warmer, less saline conditions in September and cooler, more saline conditions in October. This shift in hydrographic conditions was likely caused by an interchange of seawater masses in the area through physical oceanographic processes. In addition to changing hydrography, an influx of seawater could also bring different populations of planktonic organisms to the area, resulting in the changes in community structure and possibly the variation in ingestion observed over time. Chlorophyll $a$ values were relatively high for each sampling date; therefore, alternative prey species were abundant in each of the seawater samples.

The added Heterosigma akashiwo concentration of approximately 6000 cells ml ${ }^{-1}$ reflects the average cell density observed during a large bloom in northern Puget Sound in June 2006. This bloom lasted roughly 6 d. Smaller-scale blooms in the region in 2007 and 2009 contained slightly lower cell densities of 4000 to 5000 cells $\mathrm{ml}^{-1}$.

Overall microzooplankton community structure was not significantly affected by Heterosigma akashiwo on any of the sampling dates, despite the higher concentrations of 2850 to 6690 cells ml $^{-1} \mathrm{H}$. akashiwo in these experiments as compared to those with grazer cultures. Nevertheless, decreased abundance of large ciliates, slight changes in grazer size structure, and ingestion of the alga by certain microzooplankton species were observed.

Heterosigma akashiwo negatively affected the growth of large ciliates $\geq 40 \mu \mathrm{m}$ in length. Previous observations have shown mixed responses of this grazer group to the alga. Clough \& Strom (2005) found H. akashiwo to be toxic to laboratory cultures of 2 ciliate species within these size classes; however, a negative response to the alga was not observed in our dual-prey experiment with Strombidinopsis acuminatum. Additionally, a natural bloom of $H$. akashiwo in Japan was not toxic to large aloricate ciliates, yet significant changes within the microzooplankton community did occur (Kamiyama et al. 2000). Large decreases in tintinnid ciliates have been observed during $H$. akashiwo blooms in Rhode Island (Verity \& Stoecker 1982) and
Japan (Kamiyama et al. 2000). The tintinnid ciliates in our study were primarily Eutintinnus spp., which are too small to ingest $H$. akashiwo and were likely unaffected by the alga for this reason. Alternatively, Kamiyama et al. (2000) found an increase in the abundance of Gymnodinium sanguineum at the beginning of the bloom. Likewise, a small increase in Gymnodinium/Gyrodinium dinoflagellates occurred in this study on 24 and 26 September; however, the trend was too variable for changes to be significant. The increase in this grazer type coincided with the measurable ingestion of $H$. akashiwo by the same group. It appears that ingestion of the alga promoted the growth of this grazer type. Similarly, other microzooplankton species have been shown to ingest and grow on $H$. akashiwo. Growth rates of the prostomatid ciliate Tiarina fusus (Jeong et al. 2002) and the dinoflagellate Oxyrrhis marina (Jeong et al. 2003) increased with increasing concentrations of the alga to reach maximum rates of 0.10 and $1.43 \mathrm{~d}^{-1}$, respectively. Both grazers also ingested the alga at rates of 6.5 and $1.25 \mathrm{ngC}$ grazer $^{-1}$ $\mathrm{d}^{-1}$, respectively. The latter 2 studies did not report which $H$. akashiwo strain was used, and it may be that different strains are the cause of different grazer responses to the alga.

As revealed by epifluorescence microscopy, most microzooplankton avoided ingesting Heterosigma akashiwo; however, an aloricate ciliate, a Gyrodinium/ Gymnodinium dinoflagellate, and a round dinoflagellate were observed to measurably ingest the alga. These 3 grazers constituted a small enough proportion of the total community that overall community grazing rates $\left(g, \mathrm{~d}^{-1}\right)$ remained close to zero for all dates, except 5 October. The high grazing rate on that date was probably due to the presence of one or more large invertebrate species which were not excluded by the seawater screening process. Microzooplankton grazing most likely did not cause the high grazing rate, because ingestion as observed by epifluorescence microscopy was negligible on that date. Interestingly, each grazer type that ingested $H$. akashiwo ingested the alga on only 1 date, except for the Gyrodinium/ Gymnodinium dinoflagellate which ingested the alga on both 24 and 26 September. It may be that these particular species were not present on the other dates; however, morphologically similar grazers were observed on some of the other dates. Only a general identification of grazers was performed; therefore, each grazer type identified could consist of multiple species with potentially different feeding behaviors. Consequently, it is difficult to determine whether changes in ingestion patterns are due to a change in species composition or a change in the feeding behavior of those species. A change in feeding behavior could occur with shifts in physiological condition of the grazer, such as 
cellular nutrient concentrations (Smalley et al. 2003) and growth stage (Strom 2002), or environmental conditions such as temperature (Kleppel 1992) and light level (Strom 2002), although preliminary experiments within our study showed that light level did not affect ingestion rate. More work in this area is needed to clarify the relationships between environmental conditions, cellular characteristics, and ingestion rate.

Previous studies have found community grazing on Heterosigma akashiwo to be much higher than that observed in this study. Microzooplankton grazing on $H$. akashiwo during 3 separate natural blooms in Delaware's Inland Bays ranged from 0.88 to $1.88 \mathrm{~d}^{-1}$ (Demir et al. 2008). Grazing on H. akashiwo was much higher than on the total phytoplankton community, which ranged from 0.11 to $0.28 \mathrm{~d}^{-1}$. Heterosigma akashiwo concentrations used in our study were within the range observed by Demir et al.; however, an acclimated community within the Delaware blooms may be a cause for the higher grazing rates. Community composition was not reported by Demir et al. (2008) and thus cannot be evaluated as another likely cause for different grazing rates between studies. Microzooplankton grazing pressure has also been shown to be strong on other harmful species (Calbet et al. 2003), yet the effects of grazing on bloom development and regulation are variable and outcomes may be situationspecific (Turner \& Tester 1997).

Examinations of natural blooms differ from those in our study in that they observe a microzooplankton community which has acclimated to the increasing concentrations of harmful algae. Grazers that can ingest and grow on the harmful algal species will be favored and likely respond by increasing their own feeding rates and abundances. In contrast, our study observed the effects of Heterosigma akashiwo on a naïve community within $24 \mathrm{~h}$ of exposure. Had the incubation time been longer, higher grazing rates and more significant changes to the community may have been observed. In addition, a stronger treatment effect may have occurred with a higher, yet still ecologically relevant, concentration of $H$. akashiwo.

\section{Implications for harmful algal blooms}

Certain microzooplankton grazers exhibit a toxic response when exposed to Heterosigma akashiwo, which appears to be induced by ingestion of the alga. Ingestion-related toxicity likely influences the feeding preferences of affected grazers and may contribute to the observed low ingestion of the alga. H. akashiwo commonly occurs as only 1 member of a multi-species phytoplankton assemblage. Mixed-prey assemblages allow microzooplankton to preferentially feed on alter- nate prey and decrease, or avoid, ingestion of $H$. akashiwo, thereby decreasing the toxicity of the alga.

This pattern promotes bloom formation by dual means. First, grazing mortality of Heterosigma akashiwo is reduced, allowing growth of the species to remain stable, or increase, as environmental or physiological conditions permit. Second, community grazing pressure is focused on alternate prey, thereby decreasing the abundance of potential competitor species. Reducing interspecific competition increases resource availability to $H$. akashiwo and thus the potential growth rate of the alga. The combination of these 2 processes significantly contributes to the growth and persistence of $H$. akashiwo blooms.

Acknowledgements. We thank B. Bingham and G. MullerParker for valuable advice; K. Fredrickson, K. Bright, and J. Apple for technical support; and C. Haug, G. McKeen, and N. Schwarck for assistance with field collection and laboratory equipment. Financial support was provided by NOAA ECOHAB grant NA06NOS4780248, NSF grant OCE0551436, and Western Washington University's Department of Environmental Science.

\section{LITERATURE CITED}

Black EA, Whyte JNC, Bagshaw JW, Ginther NG (1991) The effects of Heterosigma akashiwo on juvenile Oncorhynchus tshawytscha and its implications for fish culture. J Appl Ichthyol 7:168-175

Calbet A, Landry MR (2004) Phytoplankton growth, microzooplankton grazing, and carbon cycling in marine systems. Limnol Oceanogr 49:51-57

Calbet A, Vaqué D, Felipe J, Vila M, Sala MM, Alcaraz M, Estrada M (2003) Relative grazing impact of microzooplankton and mesozooplankton on a bloom of the toxic dinoflagellate Alexandrium minutum. Mar Ecol Prog Ser 259:303-309

Clough J, Strom S (2005) Effects of Heterosigma akashiwo (Raphidophyceae) on protist grazers: laboratory experiments with ciliates and heterotrophic dinoflagellates. Aquat Microb Ecol 39:121-134

Colin SP, Dam HG (2002) Testing for toxic effects of prey on zooplankton using sole versus mixed diets. Limnol Oceanogr 47:1430-1437

Demir E, Coyne KJ, Doblin MA, Handy SM, Hutchins DA (2008) Assessment of microzooplankton grazing on Heterosigma akashiwo using a species-specific approach combining quantitative real-time PCR (QPCR) and dilution methods. Microb Ecol 55:583-594

$>$ Egloff DA (1986) Effects of Olisthodiscus luteus on the feeding and reproduction of the marine rotifer Synchaeta cecilia. J Plankton Res 8:263-274

Frost BW (1972) Effects of size and concentration of food particles on the feeding behavior of the marine planktonic copepod Calanus pacificus. Limnol Oceanogr 6:805-815

Graham LE, Wilcox LW (2000) Algae. Prentice Hall, Upper Saddle River, NJ

Hansen PJ (1995) Growth and grazing response of a ciliate feeding on the red tide dinoflagellate Gyrodinium aureolum in monoculture and in mixture with a non-toxic alga. Mar Ecol Prog Ser 121:65-72

Hedges JI, Stern JH (1984) Carbon and nitrogen determina- 
tions of carbonate-containing solids. Limnol Oceanogr 29: $657-663$

Heinbokel JF (1978) Studies on the functional role of tintinnids in the Southern California Bight. I. Grazing and growth rates in laboratory cultures. Mar Biol 47:177-189

Honjo T (1993) Overview on bloom dynamics and physiological ecology of Heterosigma akashiwo. In: Smayda TJ, Shimizu Y (eds) Toxic phytoplankton blooms in the sea. Elsevier, Amsterdam, p 33-41

Honjo T (1994) The biology and prediction of representative red tides associated with fish kills in Japan. Rev Fish Sci 2:225-253

Jensen BM (2007) Spatio-temporal variability of microalgal productivity within a shallow fjord of the San Juan Archipelago, Washington. MS thesis, Western Washington University, Bellingham, WA

Jeong HJ, Yoon JY, Kim JS, Yoo YD, Seong KA (2002) Growth and grazing rates of the prostomatid ciliate Tiarina fusus on red-tide and toxic algae. Aquat Microb Ecol 28:289-297

Jeong HJ, Kim JS, Yoo YD, Kim YD and others (2003) Feeding by the heterotrophic dinoflagellate Oxyrrhis marina on the red-tide raphidophyte Heterosigma akashiwo: a potential biological method to control red tides using mass-cultured grazers. J Eukaryot Microbiol 50:274-282

Jeong HJ, Kim JS, Song JY, Kim JH, Kim TH, Kim SK, Kang NS (2007) Feeding by protists and copepods on the heterotrophic dinoflagellates Pfiesteria piscicida, Stoeckeria algicida, and Luciella masanensis. Mar Ecol Prog Ser 349: 199-211

Jeong HJ, Kim JS, Yoo YD, Kim ST, and others (2008) Control of the harmful alga Cochlodinium polykrikoides by the naked ciliate Strombidinopsis jeokjo in mesocosm enclosures. Harmful Algae 7:368-377

Kamiyama T, Arima S (2001) Feeding characteristics of 2 tintinnid ciliate species on phytoplankton including harmful species: effects of prey size on ingestion rates and selectivity. J Exp Mar Biol Ecol 257:281-296

Kamiyama T, Matsuyama Y (2005) Temporal changes in the ciliate assemblage and consecutive estimates of their grazing effect during the course of a Heterocapsa circularisquama bloom. J Plankton Res 27:303-311

Kamiyama T, Itakura S, Nagasaki K (2000) Changes in microbial loop components: effects of a harmful algal bloom formation and its decay. Aquat Microb Ecol 21:21-30

Keppler CJ, Hoguet J, Smith K, Ringwood AH, Lewitus AJ (2005) Sublethal effects of the toxic alga Heterosigma akashiwo on the southeastern oyster (Crassostrea virginica). Harmful Algae 4:275-285

Khan S, Arakawa O, Onoue Y (1997) Neurotoxins in a toxic red tide of Heterosigma akashiwo (Raphidophyceae) in Kagoshima Bay, Japan. Aquac Res 28:9-14

Kleppel GS (1992) Environmental-regulation of feeding and egg-production by Acartia tonsa off southern California. Mar Biol 112:57-65

Livingston RJ (2007) Phytoplankton bloom effects on a gulf estuary: water quality changes and biological response. Ecol Appl 17:S110-S128

Matsuyama Y, Miyamoto M, Kotani Y (1999) Grazing impacts of the heterotrophic dinoflagellate Polykrikos kofoidii on a bloom of Gymnodinium catenatum. Aquat Microb Ecol $17: 91-98$

Nakamura Y, Suzuki S, Hiromi J (1996) Development and

Editorial responsibility: Klaus Jürgens,

Rostock, Germany collapse of a Gymnodinium mikimotoi red tide in the Seto Inland Sea. Aquat Microb Ecol 10:131-137

Oda T, Nakamura A, Shikayama M, Kawano I, Ishimatsu A, Muramatsu T (1997) Generation of reactive oxygen species by raphidophycean phytoplankton. Biosci Biotechnol Biochem 61:1658-1662

Roff JC, Hopcroft RR (1986) High precision microcomputer based measuring system for ecological research. Can J Fish Aquat Sci 43:2044-2048

Rosetta CH, McManus GB (2003) Feeding by ciliates on 2 harmful algal bloom species, Prymnesium parvum and Prorocentrum minimum. Harmful Algae 2:109-126

Sherr EB, Sherr BF (1994) Bacterivory and herbivory: key roles of phagotrophic protists in pelagic food webs. Microb Ecol 28:223-235

Smalley GW, Coats DW, Stoecker DK (2003) Feeding in the mixotrophic dinoflagellate Ceratium furca is influenced by intracellular nutrient concentrations. Mar Ecol Prog Ser 262:137-151

Smayda TJ (1997) Harmful algal blooms: their ecophysiology and general relevance to phytoplankton blooms in the sea. Limnol Oceanogr 42:1137-1153

Smayda TJ (1998) Ecophysiology and bloom dynamics of Heterosigma akashiwo (Raphidophyceae). In: Anderson DM, Cembella AD, Hallegraeff GM (eds) Physiological ecology of harmful algal blooms. NATO ASI Series G, SpringerVerlag, Heidelberg, p 113-131

Stoecker DK, Gallager SM, Langdon CJ, Davis LH (1995) Particle capture by Favella sp. (Ciliata, Tintinnnina). J Plankton Res 17:1105-1124

Strom SL (2002) Novel interactions between phytoplankton and microzooplankton: their influence on the coupling between growth and grazing rates in the sea. Hydrobiologia 480:41-54

Taniguchi A, Takeda Y (1988) Feeding rate and behavior of the tintinnid ciliate Favella taraikaensis, observed with a high speed VTR system. Mar Microb Food Webs 3:21-34

Turner JT, Tester PA (1997) Toxic marine phytoplankton, zooplankton grazers, and pelagic food webs. Limnol Oceanogr 42:1203-1214

> Twiner MJ, Trick CG (2000) Possible physiological mechanisms for production of hydrogen peroxide by the ichthyotoxic flagellate Heterosigma akashiwo. J Plankton Res 22: 1961-1975

> Twiner MJ, Dixon SJ, Trick CG (2004) Extracellular organics from specific cultures of Heterosigma akashiwo (Raphidophyceae) irreversibly alter respiratory activity in mammalian cells. Harmful Algae 3:173-182

Verity PG (1991) Measurement and simulation of prey uptake by marine planktonic ciliates fed plastidic and aplastidic nanoplankton. Limnol Oceanogr 36:729-750

Verity PG, Stoecker D (1982) Effects of Olisthodiscus luteus on the growth and abundance of tintinnids. Mar Biol 72: $79-87$

Watras CJ, Garcon VC, Olson RJ, Chisholm SW, Anderson DM (1985) The effect of zooplankton grazing on estuarine blooms of the toxic dinoflagellate Gonyaulax tamarensis. J Plankton Res 7:891-908

Yang CZ, Albright LJ, Yousif AN (1995) Oxygen-radicalmediated effects of the toxic phytoplankter Heterosigma carterae on juvenile rainbow trout Oncorhynchus mykiss. Dis Aquat Org 23:101-108

Submitted: June 17, 2009; Accepted: November 23, 2009 Proofs received from author(s): March 24, 2010 